\title{
Glucose 6-phosphate dehydrogenase deficiency enhances germ cell apoptosis and causes defective embryogenesis in Caenorhabditis elegans
}

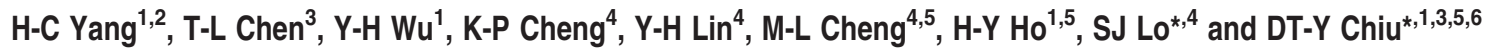

Glucose 6-phosphate dehydrogenase (G6PD) deficiency, known as favism, is classically manifested by hemolytic anemia in human. More recently, it has been shown that mild G6PD deficiency moderately affects cardiac function, whereas severe G6PD deficiency leads to embryonic lethality in mice. How G6PD deficiency affects organisms has not been fully elucidated due to the lack of a suitable animal model. In this study, G6PD-deficient Caenorhabditis elegans was established by RNA interference (RNAi) knockdown to delineate the role of G6PD in animal physiology. Upon G6PD RNAi knockdown, G6PD activity was significantly hampered in $C$. elegans in parallel with increased oxidative stress and DNA oxidative damage. Phenotypically, G6PD-knockdown enhanced germ cell apoptosis (2-fold increase), reduced egg production ( $65 \%$ of mock), and hatching ( $10 \%$ of mock). To determine whether oxidative stress is associated with G6PD knockdown-induced reproduction defects, $C$. elegans was challenged with a short-term hydrogen peroxide $\left(\mathrm{H}_{2} \mathrm{O}_{2}\right)$. The early phase egg production of both mock and G6PD-knockdown C. elegans were significantly affected by $\mathrm{H}_{2} \mathrm{O}_{2}$. However, $\mathrm{H}_{2} \mathrm{O}_{2}$-induced germ cell apoptosis was more dramatic in mock than that in G6PD-deficient $C$. elegans. To investigate the signaling pathways involved in defective oogenesis and embryogenesis caused by G6PD knockdown, mutants of p53 and mitogen-activated protein kinase (MAPK) pathways were examined. Despite the upregulation of CEP-1 (p53), cep-1 mutation did not affect egg production and hatching in G6PD-deficient $C$. elegans. Neither pmk-1 nor mek-1 mutation significantly affected egg production, whereas sek-1 mutation further decreased egg production in G6PD-deficient $C$. elegans. Intriguingly, loss of function of sek-1 or mek-1 dramatically rescued defective hatching (8.3- and 9.6fold increase, respectively) induced by G6PD knockdown. Taken together, these findings show that G6PD knockdown reduces egg production and hatching in $C$. elegans, which are possibly associated with enhanced oxidative stress and altered MAPK pathways, respectively.

Cell Death and Disease (2013) 4, e616; doi:10.1038/cddis.2013.132; published online 2 May 2013

Subject Category: Experimental Medicine

Glucose 6-phosphate dehydrogenase (G6PD) is the ratelimiting enzyme in the pentose phosphate pathway. G6PD converts glucose-6-phosphate into 6-phosphogluconolactone with the concomitant production of nicotinamide adenine dinucleotide phosphate (NADPH), a reducing equivalent necessary for reductive biosynthesis and redox homeostasis. ${ }^{1-3}$ Human G6PD deficiency is the most common enzymopathy affecting millions of people worldwide. The clinical manifestations of G6PD deficiency include jaundice, favism, and drug or infection-induced hemolytic anemia. ${ }^{2-4}$

As most of the clinical presentations of G6PD-deficiency are related to hemolytic anemia, G6PD studies in the literature have been mostly focused on erythrocytes. ${ }^{5-9}$ However, during the past decade, accumulating evidence has demonstrated that G6PD deficiency also affects nucleated cells ${ }^{10-14}$ and cellular pathophysiological events, including dysregulated cell proliferation, accelerated cellular senescence, enhanced susceptibility to viral infection, and impaired embryonic development. ${ }^{15,16}$ G6PD is essential for normal cell growth and survival. For example, G6PD-deficient fibroblasts exhibit retarded growth and premature senescence. ${ }^{10}$ Ectopic expression of G6PD alleviates the growth defect and cellular senescence caused by G6PD deficiency. Furthermore, G6PD-deficient fibroblasts are highly

\footnotetext{
${ }^{1}$ Department of Medical Biotechnology and Laboratory Sciences, College of Medicine, Chang Gung University, Tao-Yuan, Taiwan; ${ }^{2}$ Chang Gung Molecular Medicine Research Center, Chang Gung University, Tao-Yuan, Taiwan; ${ }^{3}$ Graduate Institute of Biomedical Sciences, College of Medicine, Chang Gung University, Tao-Yuan, Taiwan; ${ }^{4}$ Department of Biomedical Sciences, College of Medicine, Chang Gung University, Tao-Yuan, Taiwan; ${ }^{5}$ Healthy Aging Research Center, Chang Gung University, Tao-Yuan, Taiwan and ${ }^{6}$ Department of Laboratory Medicine, Chang Gung Memorial Hospital, Tao-Yuan, Taiwan

*Corresponding author: SJ Lo, Department of Biomedical Sciences, College of Medicine, Chang Gung University, Kwei-Shan, Tao-Yuan 333, Taiwan. Tel: + 88632118800 3295; Fax: + 88632118700 ; E-mail: losj@mail.cgu.edu.tw

or DT-Y Chiu, Department of Medical Biotechnology and Laboratory Sciences, Chang Gung University, Kwei-Shan, Tao-Yuan 333, Taiwan. Tel: + 886321188005097 or 3708; Fax: + 88632118540 , E-mail: dtychiu@ mail.cgu.edu.tw

Keywords: C. elegans; G6PD; oxidative stress; germ cell apoptosis; embryogenesis; MAPK

Abbreviations: G6PD, glucose 6-phosphate dehydrogenase; $C$. elegans, Caenorhabditis elegans; ROS, reactive oxygen species; NADPH, nicotinamide adenine dinucleotide phosphate; MAPK, mitogen-activated protein kinase; mRNA, messenger RNA; PCR, polymerase chain reaction; RNAi, RNA interference; 8-OHdG, 8-hydroxy-2-deoxyguanosine; DCFDA, 2', $7^{\prime}$ dichlorodihydrofluoroscein diacetate; $\mathrm{H}_{2} \mathrm{O}_{2}$, hydrogen peroxide

Received 03.2.13; revised 14.3.13; accepted 18.3.13; Edited by G Raschellá
} 
susceptible to hydrogen peroxide $\left(\mathrm{H}_{2} \mathrm{O}_{2}\right)$-induced senescence. ${ }^{11}$ The susceptibility to oxidative stress-induced cytotoxic effect in G6PD-depleted cells is a recurring theme. Recently, G6PD-knockdown HepG2 cells have been shown to be highly susceptible to diamide-induced cytotoxicity with concomitant increased membrane peroxidation and cytoskeletal protein aggregation. ${ }^{12}$ Such enhanced susceptibility to diamide-induced oxidative stress has been attributed mainly to impaired glutathione regeneration. These observations suggest that G6PD-deficient cells are predisposed to imbalanced redox status and oxidative stress. As a result, the increased oxidative stress elicits oxidative damage in macromolecules, such as DNA, protein, and lipid. Indeed, elevated DNA oxidative damage is found in G6PD-deficient fibroblasts, ${ }^{11}$ and such cumulative genotoxic insult impairs cell growth. ${ }^{17}$ The mitogen-activated protein kinase (MAPK) signaling pathway is involved in coordinating the response to oxidative stress, ${ }^{18}$ thereby modulating cellular events including proliferation, differentiation, stress adaptation, and apoptosis. Recently, it has been shown that G6PD-knockdown human HepG2 cells are sensitive to oxidant-induced apoptosis due to altered MAPK signaling pathway. ${ }^{13}$

Although much progress have been made on understanding the cellular effects of G6PD deficiency in erythrocytes and nucleated cells, the role of G6PD at the level of multicellular organism has not been investigated extensively due to the lack of G6PD-deficient animal model. The free-living soil nematode, Caenorhabditis elegans, is the first multicellular animal with its genome being fully sequenced ${ }^{19}$ and the C. elegans G6PD protein shows $56 \%$ amino-acid sequence homology with the human counterpart. In addition, the advantages of using $C$. elegans, including short life span, ease for large-scale culture, transparent body for microscopic examination, and readily frozen for storage as well as tractable genetic system, make it an invaluable animal model for G6PD research as well as other biomedical research. ${ }^{20-22}$

In the present study, we used RNA interference (RNAi) knockdown technique to establish a reproducible G6PDdeficient $C$. elegans animal model. Such G6PD-knockdown C. elegans displayed defective oogenesis (increased apoptotic germ cells and reduced egg production) with concomitant increase of oxidative stress and DNA oxidative damage. Most importantly, we have found that G6PD-knockdown C. elegans displayed a severe defect in embryogenesis as indicated by a dramatic reduction of hatching of the embryos from these animals. Mechanistically, the reduced egg production and defective hatching induced by G6PD deficiency could be attributed partly to increased oxidative stress and possibly mediated by altered MAPK pathways in $C$. elegans, respectively.

\section{Results}

High degree of conservation in G6PD gene from nematode to human. G6PD is ubiquitously present in living organisms from bacteria to mammals. Based on the aminoacid sequence alignment (Figure 1a), mouse (Mus musculus) G6PD shows the highest homology (93\%) compared with human (Homo sapiens) G6PD, followed by zebrafish (Danio rerio, 74\%), fruit fly (Drosophila melanogaster, 61\%), nematode (C. elegans, 56\%), yeast (Saccharomyces cerevisiae, 45\%), and bacteria (Escherichia coli, 34\%). Similar to eukaryotic G6PD homologues, including fruit fly, zebrafish, and mouse, C. elegans G6PD contains a shorter amino terminus compared with human counterpart (Figure 1a). In addition, C. elegans G6PD is separated from multicellular eukaryotic and microbial G6PD homologues in the phylogenetic tree (Figure 1b). Although microbial G6PD homologues display lower degree of conservation compared with human counterpart, it has been shown that the bacterial form of G6PD exerts antioxidant activity in G6PD-nullizygous mouse embryonic stem cells. ${ }^{23}$ Based on the high degree of conservation between $C$. elegans and human, it is speculated that $C$. elegans G6PD is a functional homologue of human G6PD.

Generation of G6PD-deficient $C$. elegans by G6PD knockdown. To investigate the effect of G6PD deficiency in $C$. elegans, RNAi knockdown technique was employed to inhibit the endogenous G6PD expression. By measuring G6PD status, including mRNA, protein, and enzymatic activity in G6PD-RNAi knockdown (Gi) C. elegans, the knockdown efficiency was determined (Figure 2). As expected, a marked reduction of g6pd mRNA level was detected in Gi C. elegans (22\% of mock, $P<0.005, N=4$ ) (Figure 2a). In addition, western blot analysis using antihuman G6PD polyclonal antibody showed diminished G6PD protein level in $\mathrm{Gi} C$. elegans compared with mock (Figure 2b, inlet). Consistent with the downregulated G6PD protein expression, a significant decrease of G6PD catalytic activity was detected in Gi C. elegans (11\% of mock, $P<0.005, N=8$ ) (Figure 2b). The residual G6PD activity $(11 \%)$ in Gi C. elegans was in good accord with our recent report in G6PD-knockdown human cell line. ${ }^{13}$ Despite significant depletion of G6PD, no vital growth defects were observed in the first generation of $\mathrm{Gi} C$. elegans compared to mock $C$. elegans under our experimental condition. Taken together, these results demonstrate that G6PD knockdown in $C$. elegans is reproducible in the generation of a viable G6PD-deficient animal model.

Increased oxidative stress and DNA oxidative damage by G6PD knockdown in $\boldsymbol{C}$. elegans. G6PD-depleted cells are highly susceptible to oxidative stress-induced cytotoxic effect with the concomitant generation of reactive oxygen species (ROS) and oxidative damage. ${ }^{11,12}$ In order to test whether G6PD knockdown increased oxidative stress in C. elegans, the level of oxidative stress and oxidative damage were determined (Figure 3). By incubating first-day C. elegans adult with ROS-sensitive fluorescent dye $2^{\prime}, 7^{\prime}$ dichlorodihydrofluoroscein diacetate (DCFDA), increased ROS was detected in Gi $C$. elegans compared with mock C. elegans (1.2-fold, $P=0.038, N=6$ ) (Figure 3a). To further investigate whether G6PD deficiency caused oxidative damage in macromolecues, malondialdehyde (MDA) and 8-hydroxy-2-deoxyguanosine (8-OHdG) were measured. While there was no significant difference of MDA level between mock and Gi $C$. elegans (data not shown), 8-OHdG level was significantly increased in $\mathrm{Gi} C$. elegans compared to mock (1.5-fold, $P=0.005, N=6$ ) (Figure $3 b$ ). This finding 
a Hs MGRRGSAPGNGRTLRGCERGGRRRRSADSVMAEQVALSRTQVCGILREELFQGDAFHQSD 60 Dr ----------------MGSRASADKMSLPLSRSEVFGQLRKELHDDTAFHOSD 37

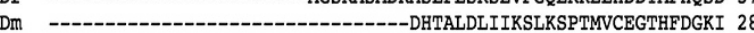
Ce --------------------------MACKRHSVSDPISKDLVECLRESMQRDLKFET 32 MSEGPVKFK 10 -MAVTQTAQ 8

HS THIFIIMGASGDLAKKKIYPTIWWLFRDLLPENTFIVGYARSRLTVAD-----IRKOSEP 116 Dr VHIFIIMGASGDLAKKKIYPTLWWLFRDGLLPEQTYFVGFARSDLTVDA----IRIACMP 93 DM PHTFVIFGASGDLAKKKIYPTLWWLYRDDLLPKPTKFCGYARSMLTVDS----IKEQCLP 84 Ce PYVFVIFGASGDLAKKKIYPTLWWLFRDNLLPVNIKFIGYARSDLTVFK----LRESFEK 88 Ce PYVVIFGASGDOKKKIYPILWLPRDNLPVIKFIGYARDLIVK--LRESE 88 EC ACDLVIFGAKGDLARRKLLPSLYQLEKAGQLNPDTRIIGVGRADWDKAAYTKVVREALET 68 $::: * *, * * *::{ }^{*}::::^{*}:$. $^{*} \quad:{ }^{*}:{ }^{*} \quad::$

HS FFKATPEEK--LKLEDFFARNSYVAGOYDDAASYORLNSHMNALH---LGSOANRLFYLA 171 Mm FFKATPEER--PKLEEFFARNSYVAGQYDDAASYKHLNSHMNALH---QGMQANRLFYLA 141 Dr YMKVVDNEA--ERLAAFFSRNSYISGKYVEESSFSDLNTHLLSLP---GGAEANRLFYLA 148 DM YMKVQPHEQ--KKYEEFWALNEYVSGRYDGRTGFELLNQQLEIME---NKNKANRIFYLA 139 Ce NCKVRENEK--CAFDDFIKKCSYVOGOYDTSEGFORLOSSIDDFOKESNNOAVNRLYYLA 146 Sc HLKKPHGEADDSKVEQFFKMVSYISGNYDTDEGFDELRTQIEKFEKSANVDVPHRLFYLA 127 EC FMKETIDEG---LWDTLSARLDFCNLDVNDTAAFSRLGAMLDQKN--------RITINYFA 118 * * *

HS LPPTVYEAVTKNIHESCMSQIG-WNRIIVEKPFGRDLQSSDRLSNHISSLFREDQIYRID 230 Mm LPPTVYEAVTKNIQETCMSQTG-WNRIIVEKPFGRDLQSSNQLSNHISSLFREDQIYRID 200 Dr LPPSVYHDVTKNIKHQCMSTKG-WNRVIVEKPFGRDLQSSEELSSHLSSLFTEEQIYRID 207 DM LPPSVFEEVTVNIKQICMSVCG-WNRVIIEKPFGRDDASSQALSDHLAGLFQEDQLYRID 198 Ce LPPSVFNVVSTELKKNCMDHGDSWTRVIIEKPFGHDLKSSCELSTHLAKLFKEDQIYRID 206 Sc LPPSVFLTVAKQIKSRVYAENG-ITRVIVEKPFGHDLASARELQKNLGPLFKEEELYRID 186 EC MPPSTFGAICKGLGEAKLNAKP--ARVVMEKPLGTSLATSQEINDQVGEYFEECQVYRID 176

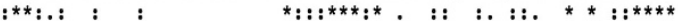

HS HYLGKEMVQNLMVLRFANRIFGPIWNRDNIACVILTFKEPFGTEGRGGYFDEFGIIRDVM 290 Mm HYLGKEMVQNLMVLRFANRIFGPIWNRDNIACVILTFKEPFGTEGRGGYFDEFGIIRDVM 260 Dr HYLGKEMVQNLMVLRFGNRIFGPIWNRDSVACVVLTFKEPFGTQGRGGYFDDFGIIRDVM 267 Dm HYLGKEMVQNLMTIRFGNKILSSTWNRENIASVLITFKEPFGTQGRGGYFDEFGIIRDVM 258 $\mathrm{Ce}$ HYLGKEMVQNLMVMRFGNRILAPSWNRDHIASVMISFKEDFGTGGRAGYFDTAGIIRDVM 266 Sc HYLGKELVKNLLVLRFGNQFLNASWNRDNIQSVQISFKERFGTEGRGGYFDSIGIIRDVM 246

EC HYLGKETVLNLLALRFANSLFVNNWDNRTIDHVEITVAEEVGIEGRWGYFDKAGQMRDMI 236

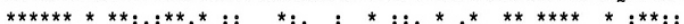

$\mathrm{Dr}$

$\mathrm{EC}$

Hs

$\mathrm{Mm}$

Dr

Sc

Hs

$\mathrm{Mm}$

Dr

Sc

EC

Hs

$\mathrm{Mm}$

$\mathrm{Dm}$

$\mathrm{Sc}$

EC

Hs
$\mathrm{Mm}$
$\mathrm{Dr}$
$\mathrm{Dm}$
$\mathrm{Ce}$
$\mathrm{Sc}$
$\mathrm{EC}$

ONHLLOMLCLVAMEKPASTNSDDVRDEKVKVLKCISEVQANNV-----VLGOYVGNPDGE- 345 ONHLLQMLCLVAMEKPATTGSDDVRDEKVKVLKCISEVETDNV-----VLGQYVGNPNGE- 315 QNHLLQMLSLVAMEKPASTSSDDVRDEKVKVLKCIEPVTLSDV-----VLGQYVGDPEGE- 322 QNHLLQILSLVAMEKPVSCHPDDIRDEKVKVLKSIEALTLDDM----VLGQYLGNPQGTN 314 ONHLMQILTLVAMEKPASLNAEDIRDEKVKVLKAAKVVELKDV----VVGQYIASPEFDH 322 ONHLLQIMTLLTMERPVSFDPESIRDEKVKVLKAVAPIDTDDV----LLGQYGKSEDGS- 301 QNHLLQILCMIAMSPPSDLSADSIRDEKVKVLKSLRRIDRSNVREKTVRGQYTAGFAQG- 295

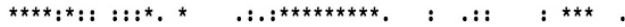

GEATKGYLDDPTVPRGSTTATFAAVVLYVENERWDGVPFILRCGKALNERKAEVRLOFHD 405 GEAANGYLDDPTVPHGSTTATFAAAVLYVENERWDGVPFILRCGKALNERKAEVRLQFRD 375 GEAKLGYLDDKTVPKGSTQATFATAVLYVKNERWDGVPFILRCGKALNERKAEVRLQFTD 382 DDARTGYVEDPTVSNDSNTPTYALGVLKINNERWQGVPFILRCGKALNERKAEVRIQYQD 374 PEASOGYKDDKSVPADSTTPTYALAVVHINNERWEGVPFFLRCGKALNEKKAEVRIOFKE 382 ---KPAYVDDDTVDKDSKCVTFAAMTFNIENERWEGVPIMMRAGKALNESKVEIRLQYKA 358 -KKVPGYLEEEGANKSSNTETFVAIRVDIDNWRWAGVPFYLRTGKRLPTKCSEVVVYFKT 354

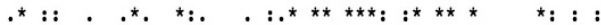

VAGDIFHQ---QCKRNELVIRVQPNEAVYTKMMTKKPGMFFNP--EESELDLTYGNRYKN 460 VAGDIFHQ---QCKRNELVIRVQPNEAVYTKMMTKKPGMFFNP--EESELDLTYGNRYKN 430 VPGDIFSS---QCRRNELVVRVQPNEAIYAKMMSKKPGVYFSP--EETELDLTYHSRYRD 437 VPGDIFEG---NTKRNELVIRVOPGEALYFKMMTKSPGITFDI--EETELDLTYEHRYKD 429 VSGDIYPSG--ELKRSELVMRVQPNEAVYMKLMTKKPGMGFGV--EETELDLTYNNRFKE 438 VASGVFKD-----IPNNELVIRVQPDAAVYLKFNAKTPGLSNAT--QVTDLNLTYASRYQD 412 PELNLFKESWQDLPQNKLTIRLQPDEGVDIQVLNKVPGLDHKHNLQITKLDLSYSETFNQ 414

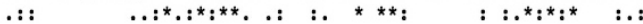

VKLPDAYERLILDVFCGSQMHFVRSDELREAWRIFTPLLHQIEL-EKPKPIPYIYGSRGP 519 VKLPDAYERLILDVFCGSQMHFVRSDELREAWRIFTPLLHKIDR-EKPQPIPYVYGSRGP 489 VKLPDAYERLILDVFCGSQMHFVRSDLREAWRIFTPLLHQIES-EKTPPIKYKYGSRGP 496 SYLPDAYERLILDVFCGSOMHFVRSDELREAWRIFTPILHOIEK-EHIRPITYQYGSRGP 488 VRLPDAYERLFLEVFMGSQINFVRTDELEYAWRILTPVLEELKK-KKVQPVQYKFGSRGP 497 FWIPEAYEVLIRDALLGDHSNFVRDDELDISWGIFTPLLKHIERPDGPTPEIYPYGSRGP 472 THLADAYERLLLETMRGIQALFVRRDEVEAWKWVDSITEAWAM-DNDAPKPYQAGTWGP 473

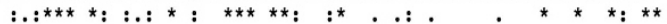

TEADELMKRVGFQYEG--TYKWVNPHKL----- 545 TEADELMKRVGFQYEG--TYKWVNPHKL----- 515 AEADELVQKVGFRYEG--TYKWVNPHKL----- 522 KEADRKCEENNFKYSG--SYKWHGGKAATSNH- 518 TEGDELMKKYGFIFTG--TYKWVAPKL------ 522 KGLKEYMQKHKYVMPEKHPYAWPVTKPEDTKDN 505 VASVAMITRDGRSWNEFE----------------- 491

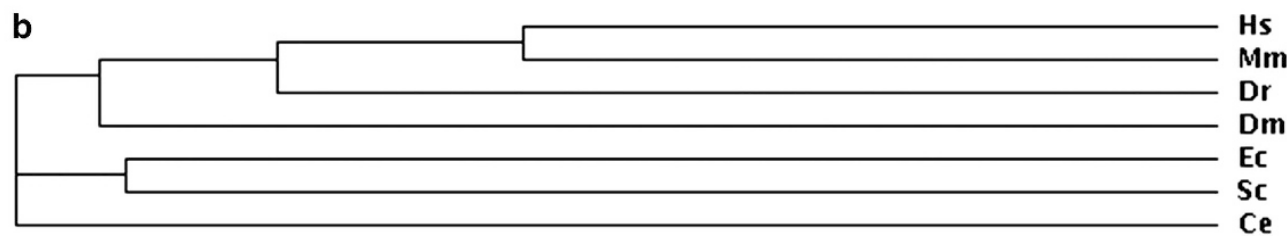

Figure 1 C. elegans G6PD shows high degree of conservation with other G6PD homologues. (a) Amino-acid sequence alignment of G6PD homologues in human (Hs), mouse $(\mathrm{Mm})$, zebrafish (Dr), fruit fly (Dm), nematode (Ce), yeast (Sc), and bacteria (Ec). (b) Phylogenetic tree of G6PD homologues. Asterisk (*) represents fully conserved residues, colon (:) represents conservation between groups of strongly similar properties, period (.) represents conservation between groups of weakly similar properties

is consistent with a previous report in G6PD-deficient cell model, ${ }^{11}$ indicating that G6PD may play a role in protecting cells against DNA oxidative damage in $C$. elegans.

Decreased egg production and hatching by G6PD knockdown in $\boldsymbol{C}$. elegans. In the first generation of $\mathrm{Gi}$ C. elegans, no significant phenotypic changes including morphology, pharyngeal pumping, mobility, and growth rate were observed (data not shown). The lack of major phenotypes upon G6PD knockdown indicated that the residual G6PD activity in $\mathrm{Gi} C$. elegans is sufficient to maintain basic cell functions in $C$. elegans (Figure 2b). Nevertheless, the brood size derived from the first generation of Gi hermaphrodite was significantly reduced (65\% of mock, $P=0.011, n=60$ ) compared with mock control (Figure 4a). This finding indicates that G6PD is required for maintaining normal egg production. In addition to the decreased egg production upon G6PD knockdown, a majority of eggs produced by
Gi $C$. elegans were unable to hatch compared with mock (10\% of mock, $P<0.005, n=60$ ) (Figure $4 \mathrm{~b}$ ). This dramatic observation is consistent with a previous report that G6PD knockdown induces embryonic lethality in $C$. elegans. ${ }^{24}$

\section{Enhanced germ cell apoptosis by G6PD knockdown in} C. elegans. In order to investigate whether decreased egg production induced by G6PD knockdown is the consequence of enhanced germ cell death, the germ cell apoptosis was determined in G6PD-deficient $C$. elegans using GFP reporter strain bcls39 ( $\mathrm{P}_{\text {lim-7 }}$ ced-1::gfp), which highlights somatic sheath cell around apoptotic germ cells upon oogenesis. ${ }^{25}$ Under basal condition, the number of apoptotic germ cells in bcls39 Gi $C$. elegans was significantly increased by 2-fold (7.4 per gonad, $P=0.04, n=80$ ) compared with bcls39 mock (3.7 per gonad, $n=60$ ) (Figure $4 \mathrm{c}$ ). This result clearly demonstrates that reduction of G6PD increases germ cell apoptosis. 

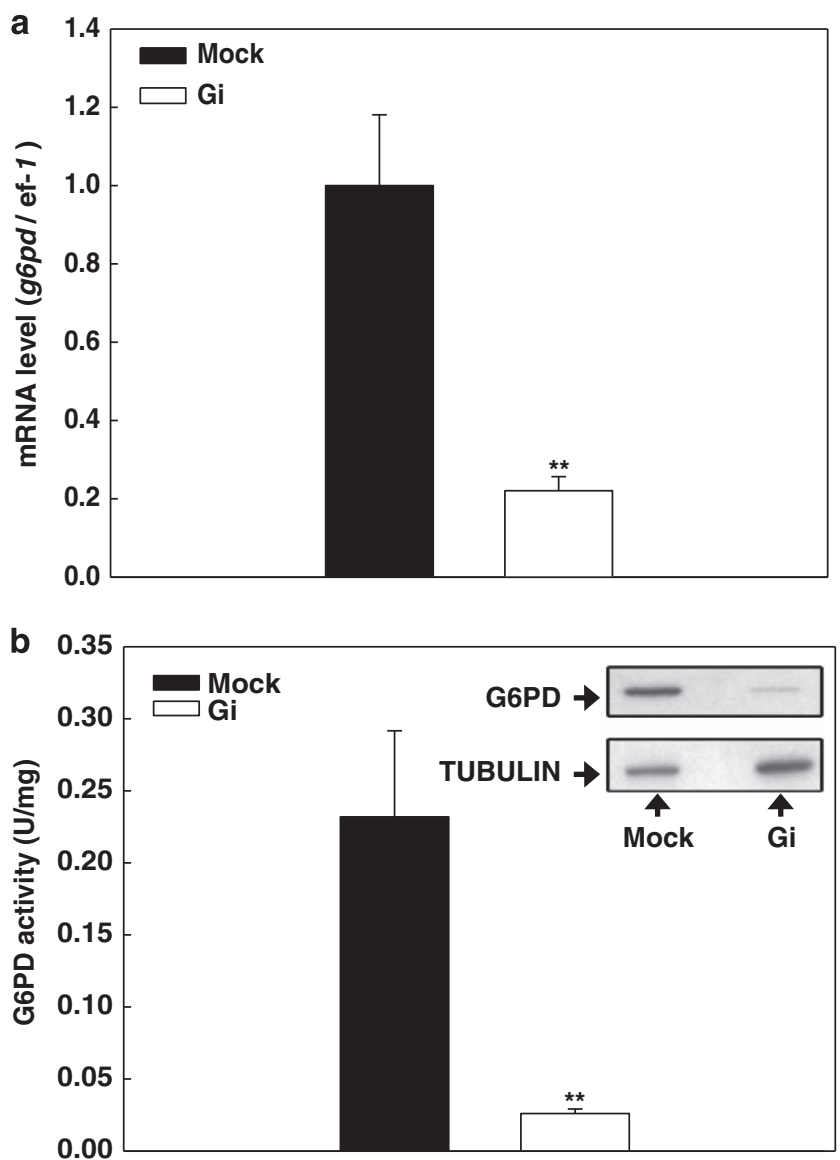

Figure 2 G6PD knockdown downregulates G6PD status. (a) g6pd mRNA level

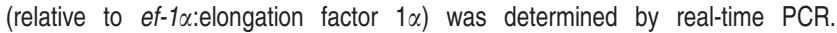
$(N=4, P<0.005)$ (b) G6PD activity was measured by enzymatic assay and protein expression was determined by western blot (inlet). $(N=8, P<0.005)$ ${ }^{* \star} P<0.005$ indicates significant difference between mock and G6PD-RNAi knockdown (Gi) C. elegans

Involvement of high oxidative stress in altered germ cell apoptosis and egg production by G6PD knockdown in C. elegans. Increased oxidative stress has been associated with reduced brood size in $C$. elegans. ${ }^{26-28}$ To test whether high oxidative stress was involved in altered germ cell apoptosis and egg production caused by G6PD knockdown, a short-term $\mathrm{H}_{2} \mathrm{O}_{2}$ treatment was exogenously applied to C. elegans adult followed by scoring the apoptotic germ cells (Figures $5 \mathrm{a}$ and b) and egg production (Figure $5 \mathrm{c}$ ). At $5 \mathrm{mM}$ and $10 \mathrm{mM} \mathrm{H}_{2} \mathrm{O}_{2}$, the apoptotic germ cells were increased in mock $C$. elegans $(6.2 \pm 1.8$ cells per gonad, $P=0.109$ and $7.5 \pm 1.9$ cells per gonad, $P<0.005$, respectively) compared with untreated control ( $3.7 \pm 1.3$ cells per gonad) (Figure $5 \mathrm{a}$ ). However, the apoptotic germ cells in $\mathrm{H}_{2} \mathrm{O}_{2}$-treated $\mathrm{Gi}$ C. elegans showed no discernible difference $(5 \mathrm{mM}$ $\mathrm{H}_{2} \mathrm{O}_{2}: 7.8 \pm 2.3$ cells per gonad, $P=0.276$ and $10 \mathrm{mM}$ $\mathrm{H}_{2} \mathrm{O}_{2}: 7.2 \pm 1.7$ cells per gonad, $P=0.652$ ) compared with untreated Gi control (7.4 \pm 1.9 cells per gonad) (Figure $5 a$ ). Furthermore, at $5 \mathrm{mM} \mathrm{H}_{2} \mathrm{O}_{2}$, the total egg production of both mock and $\mathrm{Gi} C$. elegans were not significantly affected compared with untreated control $(P=0.924$ and $P=0.832$, respectively) (Figure $5 \mathrm{c}$ and Supplementary Table $\mathrm{S1}$ ).
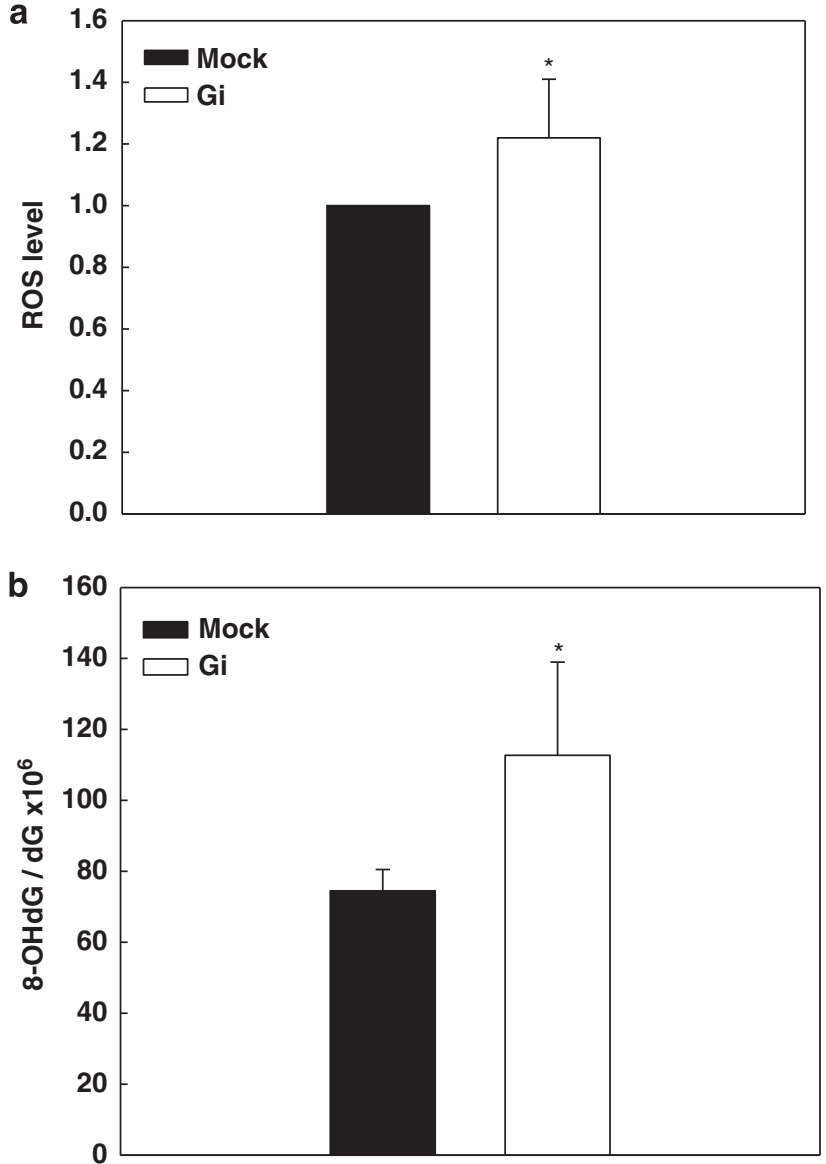

Figure 3 G6PD knockdown enhances oxidative stress and DNA oxidative damage in $C$. elegans. (a) The ROS level in $C$. elegans was determined by incubating staged adults with DCFDA and the fluorescence was detected by fluorescent microplate reader. The fluorescence of G6PD-RNAi knockdown (Gi) C. elegans was subtracted by background and normalized with mock $(N=6$, $P=0.038)$. (b) The DNA oxidative damage $(8-\mathrm{OHdG})$ in $C$. elegans was determined by isolating DNA from staged adults followed by separation by HPLC and detection by electrochemical detector. The $8-\mathrm{OHdG}$ ratio was displayed as the number of 8-OHdG molecules per $10^{6} \mathrm{dG}$. $(N=6, P=0.005){ }^{\star} P<0.05$ indicates significant difference between mock and G6PD-RNAi knockdown (Gi) $C$. elegans

Nevertheless, during the first half of egg-laying period (day 1 to day 2 ), the egg production was markedly reduced in mock and $\mathrm{Gi}$ C. elegans compared with untreated control $(72 \%$ of mock control, $P=0.013$ and $67 \%$ of Gi control, $P=0.022$, respectively), whereas no significant difference was found in the second half of egg-laying period (day 3 to day 4). Remarkably, at $10 \mathrm{mM} \mathrm{H}_{2} \mathrm{O}_{2}$, the total egg production was significantly reduced in both mock and $\mathrm{Gi} C$. elegans compared with untreated control (65\% of mock control, $P=0.010$ and $62 \%$ of Gi control, $P=0.028$, respectively). From day 1 to day 2 , the egg production was severely decreased in mock and $\mathrm{Gi}$ C. elegans compared with untreated control $(34 \%$ of mock control, $P=0.001$ and $38 \%$ of Gi control, $P=0.001$, respectively), whereas there was no significant difference in the second half of egg-laying period (day 3 to day 4). Taken together, these data indicate that high oxidative stress could be associated with G6PD knockdown-induced germ cell apoptosis and reduced egg production. 

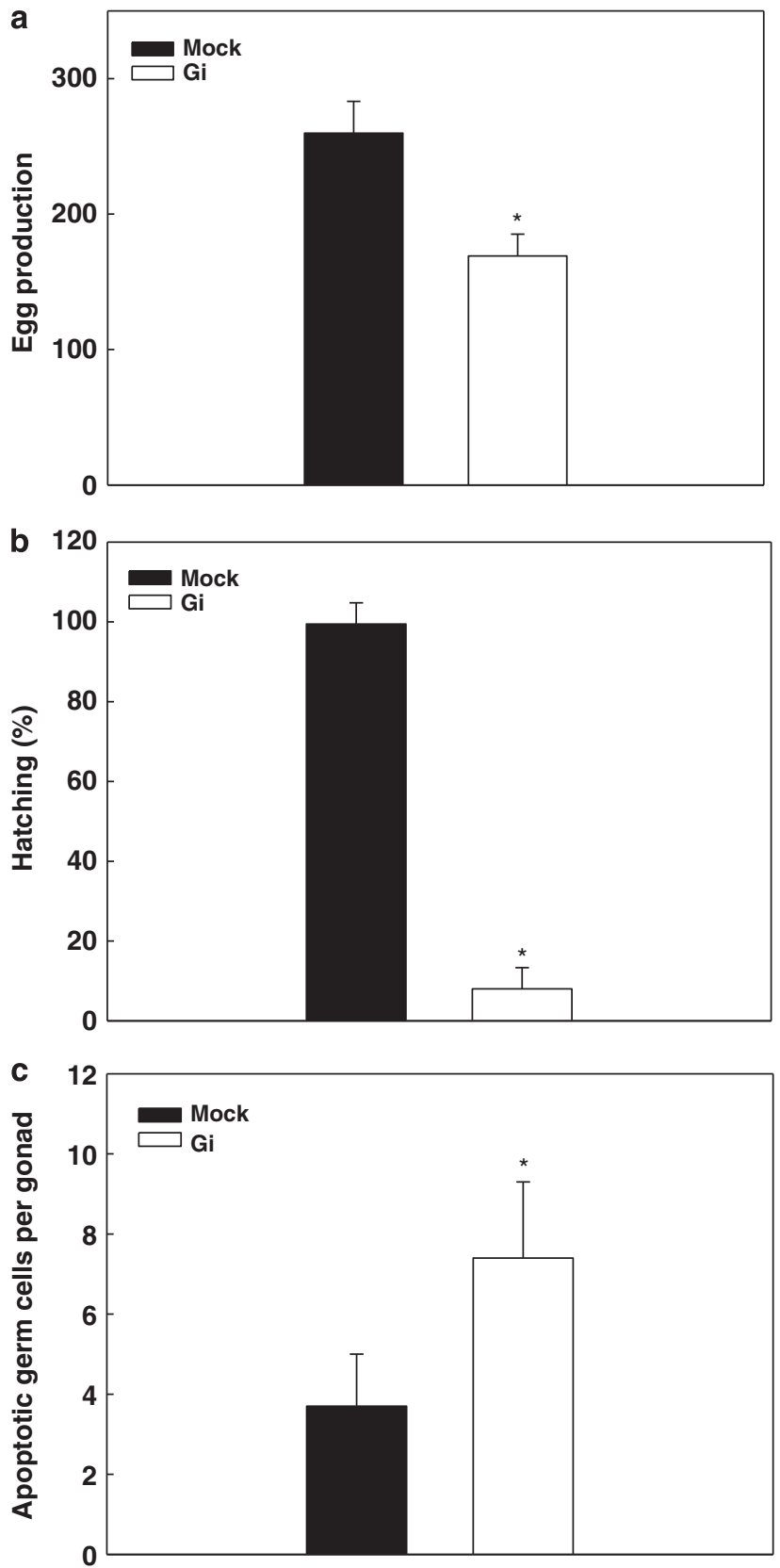

Figure 4 G6PD knockdown affects egg production, hatching, and germ cell apoptosis in $C$. elegans. (a) The total egg production was determined by counting eggs laid on plate throughout egg laying period. The assay was performed with 20 hermaphrodites in triplicate. (b) Hatching was determined by counting the total live progeny and divided by the number of total egg production. (c) The germ cell apoptosis was determined in the gonad of the GFP reporter strain bcls39 $\left(\mathrm{P}_{\text {lim- }-7} \mathrm{ced}-\right.$ $1:: g f p) .{ }^{*} P<0.05$ indicate significant difference between mock and G6PD-RNA knockdown (Gi) $C$. elegans. These results were representative of three separate experiments $(N=3)$

Other possible mechanisms of defective egg production induced by G6PD knockdown in C. elegans. In order to elucidate the signaling pathway associated with defective egg production caused by G6PD deficiency, loss-of-function mutants of possible pathways were analyzed for their egg production. It has been shown that p53 protein expression

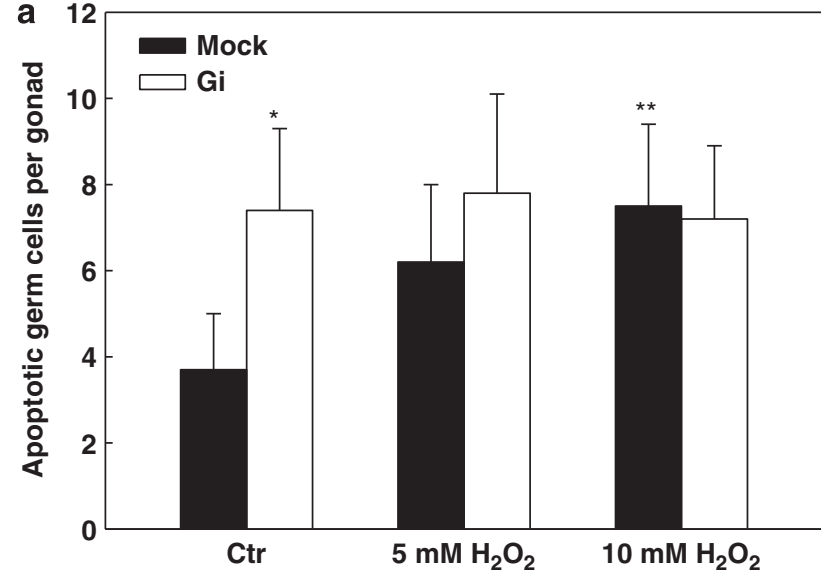

b
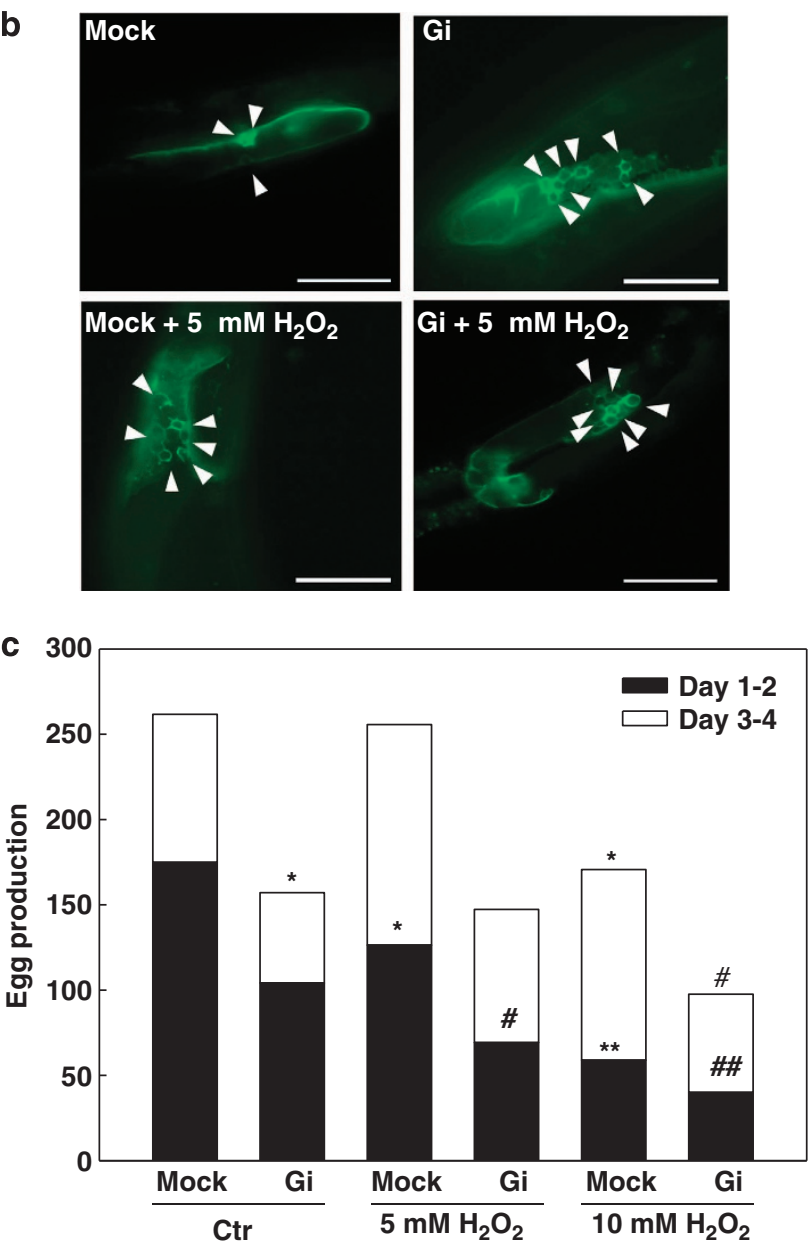

Figure 5 Short-term $\mathrm{H}_{2} \mathrm{O}_{2}$ treatment affects germ cell apoptosis and egg production in $C$. elegans. (a) The apoptotic germ cells in the gonad of adult hermaphrodite with or without $\mathrm{H}_{2} \mathrm{O}_{2}$ treatment were determined. (b) Fluorescent microscopy images of germ cell apoptosis between mock and G6PD-RNAi knockdown (Gi) $\mathrm{C}$. elegans with or without short-term $5 \mathrm{mM} \mathrm{H}_{2} \mathrm{O}_{2}$ treatment. White arrows indicate apoptotic germ cells in the gonad, scale bar $=50 \mu \mathrm{m}$. (c) The egg production of young adult hermaphrodite with or without $\mathrm{H}_{2} \mathrm{O}_{2}$ treatment was determined. The black bar represents egg production from day 1 to day 2 post-treatment, and the white bar represents egg production from day 3 to day 4 post-treatment. The stack bar represents total egg production post-treatment. ${ }^{*} P<0.05,{ }^{\star *} P<0.005$ indicate significant difference compared with untreated mock. ${ }^{\#} P<0.05,{ }^{\#} P<0.005$ indicate significant difference compared with untreated G6PD-RNAi knockdown (Gi) $C$. elegans. These results were representative of three separate experiments $(N=3)$ 
is upregulated in oxidant-treated G6PD-deficient human fibroblasts. ${ }^{11}$ Likewise, Gi $C$. elegans showed enhanced CEP-1 (p53) protein expression (1.37-fold, $P=0.014, N=5$ ) (Supplementary Figure S1). However, cep-1 mutation neither affected egg production $(P=0.313, n=70)$ nor prevented G6PD knockdown-induced defective egg production in C. elegans $(P=0.622, n=70)$ (Figure $6 \mathrm{a}$ ), indicating that reduced egg production caused by G6PD deficiency is independent to cep- 1 .

It has been shown that G6PD knockdown enhances the inhibitory effect of $\mathrm{H}_{2} \mathrm{O}_{2}$ on protein tyrosine phosphatase and causes sustained MAPK activation leading to cell demise. ${ }^{13}$ In order to investigate whether MAPK played a role in G6PD knockdown-induced defective egg production, C. elegans MAPK mutants, including pmk-1, sek-1, and mek1 were scored for their egg production under basal and G6PD knockdown conditions (Figures $6 \mathrm{~b}-\mathrm{d}$ ). Our results showed that $p m k-1$ mutant exhibited minor decrease of egg production compared to mock ( $91 \%$ of mock, $P<0.001, n=70$ ), whereas the egg production of the pmk-1/g6pd(RNAi) double mutant was similar to that of $\mathrm{Gi} C$. elegans $(P=0.136, n=70)$ (Figure 6b). On the other hand, sek-1 mutant displayed reduced egg production similar to Gi C. elegans (76\% of mock, $P<0.001, n=70)$. Notably, sek-1/g6pd(RNAi) double mutant showed further decrease of egg production (42\% of Gi $C$. elegans, $P<0.001, n=70$ ) (Figure $6 \mathrm{c}$ ). The mek-1 mutant displayed no difference of egg production compared with mock $(P=0.334, n=60)$ (Figure $6 \mathrm{~d})$. Also, the egg production of the mek-1/g6pd(RNAi) double mutant was indistinguishable to that of Gi $C$. elegans $(P=0.471, n=60)$. Taken together, these results suggest that sek-1, but not mek-1 or pmk-1, acts in parallel to G6PD in the modulation of egg production.

Involvement of MAPK pathways in defective hatching of G6PD-knockdown $\boldsymbol{C}$. elegans. Since the hatching of the embryos was severely affected by G6PD knockdown (Figure 4b), possible signaling pathways such as p53 and MAPK were examined (Figure 7). Compared with the diminished hatching of $\mathrm{Gi} C$. elegans $(8.0 \%, P<0.001$, $n=70$ ), the loss of function of cep-1/g6pd(RNAi) double mutant also displayed low hatching $(6.9 \%, P=0.408$, $n=70)$. Similarly, the $p m k-1 / g 6 p d(\mathrm{RNAi})$ double mutant exhibited low hatching compared with $\mathrm{Gi}$ C. elegans $(8.7 \%$, $P=0.568, n=70)$. Intriguingly, the hatching was significantly increased in sek-1/g6pd(RNAi) and mek-1/g6pd(RNAi) double mutants compared with Gi C. elegans (8.3-fold, $P=0.019, n=70$ and 9.6-fold, $P<0.001, n=60$, respectively). Taken together, these results suggest that sek-1 and mek-1 play essential roles in the modulation of hatching in G6PD-knockdown C. elegans embryos.

\section{Discussion}

G6PD is highly conserved from bacteria to human (Figure 1). Previous studies have shown that G6PD deletion does not affect the viability of E. coli. ${ }^{29}$ Likewise, G6PD-null $S$. cerevisiae grows normally, except for the nutritional requirement of organic sulfur. ${ }^{30}$ Mild G6PD deficiency $(40 \%$ of normal activity) moderately affects cardiac function in a mouse model. ${ }^{31}$ In contrast, severe G6PD deficiency leads to
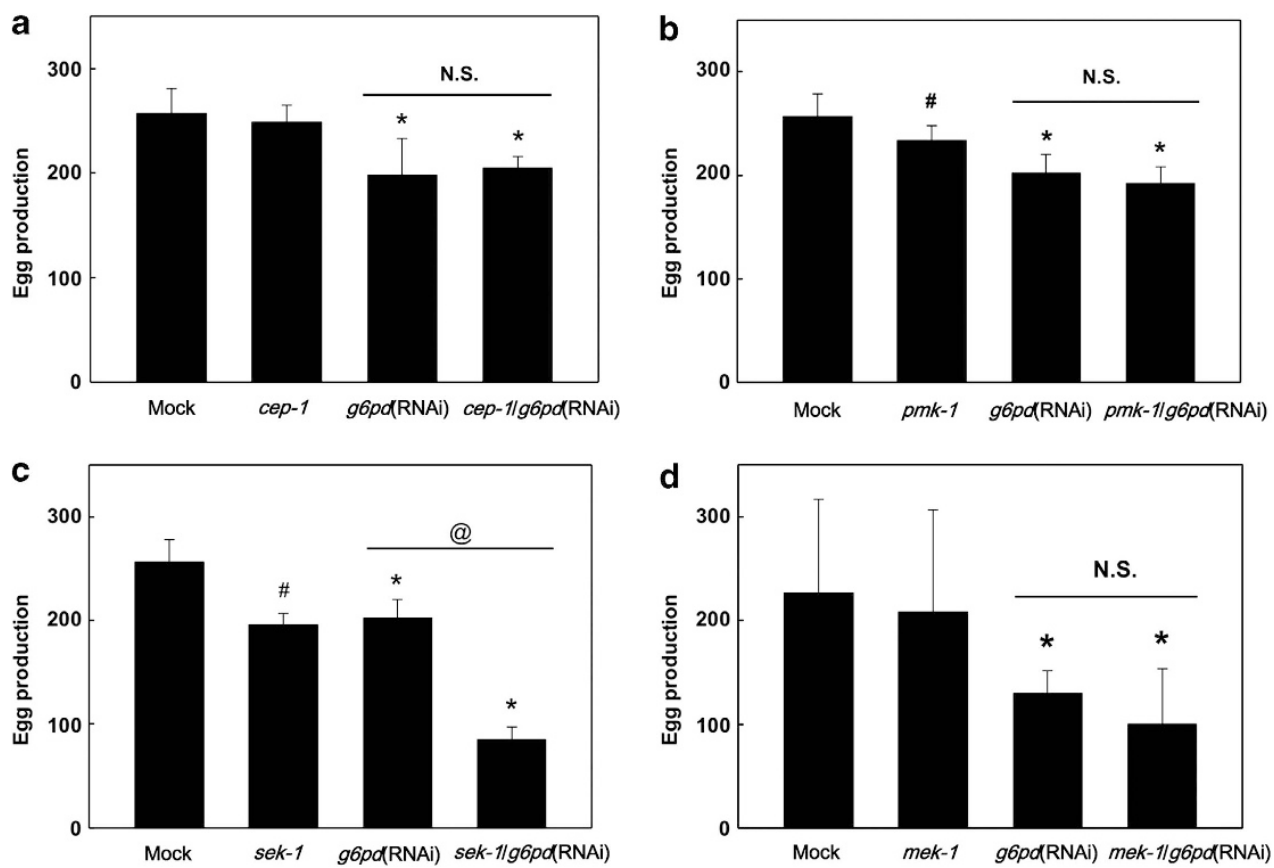

Figure 6 G6PD knockdown-induced defective egg production is independent of cep-1 and in parallel with sek-1. (a) The egg production was determined in mock, $g 6 p d(\mathrm{RNAi}), c e p-1$ and cep-1/g6pd(RNAi) double mutants. (b) The egg production was determined in mock, g6pd(RNAi), pmk-1 mutant and pmk-1/g6pd(RNAi) double mutant. (c) The egg production was determined in mock, g6pd(RNAi), sek-1 and sek-1/g6pd(RNAi) double mutants. (d) The egg production was determined in mock, g6pd(RNAi), mek-1 and mek-1/g6pd(RNAi) double mutants. ${ }^{*} P<0.05$ indicates significant difference compared with untreated G6PD-knockdown $C$. elegans. ${ }^{\#} P<0.05$ indicates significant difference compared with mock C. elegans. ${ }^{\circledR} P<0.05$ indicates significant difference between $g 6 p d($ RNAi) and sek-1/ g6pd(RNAi) $C$. elegans. N.S. indicates no significant difference 
embryonic lethality in mice. ${ }^{32}$ Currently, the lack of a workable G6PD-deficient animal model is the major obstacle to reveal the role of G6PD in organismal level. In the present study, G6PD-deficient $C$. elegans is established by RNAi knockdown as a viable and workable model system. Upon G6PD knockdown, $C$. elegans demonstrates significant reduction of G6PD expression and catalytic activity (Figure 2), which are consistent with reduced G6PD status in G6PD-knockdown cells. ${ }^{13}$

G6PD deficiency is associated with embryonic lethality in animals. Indeed, the most dramatic finding in this study is the extremely low hatching of eggs derived from G6PD-

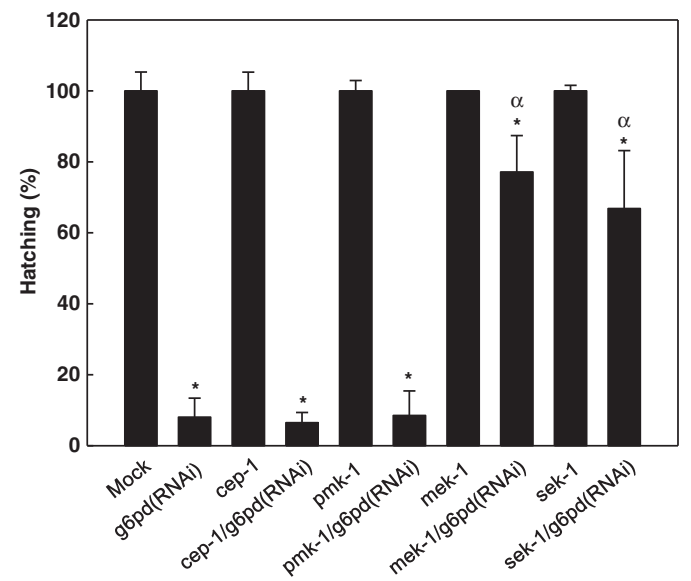

Figure 7 G6PD knockdown-induced defective hatching is reversed by sek-1 or mek-1 loss-of-function. The hatching was determined in mock, cep-1, pmk-1, mek1, sek-1 mutants and their double mutants with G6PD-RNAi knockdown. ${ }^{*} P<0.05$ indicates significant difference compared with RNAi control. ${ }^{\alpha} P<0.001$ indicates significant difference compared with G6PD-RNAi knockdown (Gi) C. elegans knockdown $C$. elegans (Figure 4c). This result is supported by previous reports in mice ${ }^{32}$ and $C$. elegans from a large-scale RNAi screen. ${ }^{24}$ Consistently, the low hatching of eggs from G6PD-knockdown C. elegans provides strong evidence to the notion that G6PD is indispensable for embryonic survival in $C$. elegans. However, the underlying mechanism on how G6PD status affects embryonic survival is largely unknown.

One possible mechanism responsible for the defective oogenesis induced by G6PD knockdown in $C$. elegans is increased oxidative stress and oxidative damage. Indeed, G6PD deficiency has been correlated with increased oxidative stress in cells. ${ }^{10-13}$ Presumably, elevated oxidative stress and oxidative damage should be present in G6PD-deficient animals. Toward this end, we have determined ROS and oxidative damage in G6PD-knockdown C. elegans. As expected, G6PD-knockdown C. elegans displays increased oxidative stress compared with mock in basal condition (Figure 3a) and such observation is comparable with G6PDknockdown cells. ${ }^{12,13}$ Previous study has shown that G6PD-knockdown cells do not display enhanced MDA under physiological condition. ${ }^{12}$ Similarly, the MDA level in G6PDknockdown $C$. elegans is indistinguishable to mock control under physiological condition (data not shown). On the other hand, G6PD knockdown enhances DNA oxidative damages in C. elegans (Figure 3b). The fact that G6PD deficiency enhances DNA oxidative damage but not lipid peroxidation suggests that G6PD-deficient $C$. elegans is particularly sensitive to genotoxic insult, which is in accord with previous finding in G6PD-deficient fibroblasts. ${ }^{11}$

Previous studies showed that increased oxidative stress is associated with defective oogenesis ${ }^{33}$ in $C$. elegans. Since DCFDA mainly stains for $\mathrm{H}_{2} \mathrm{O}_{2}$, the possibility that other ROS species contribute to elevated DNA oxidative damage in

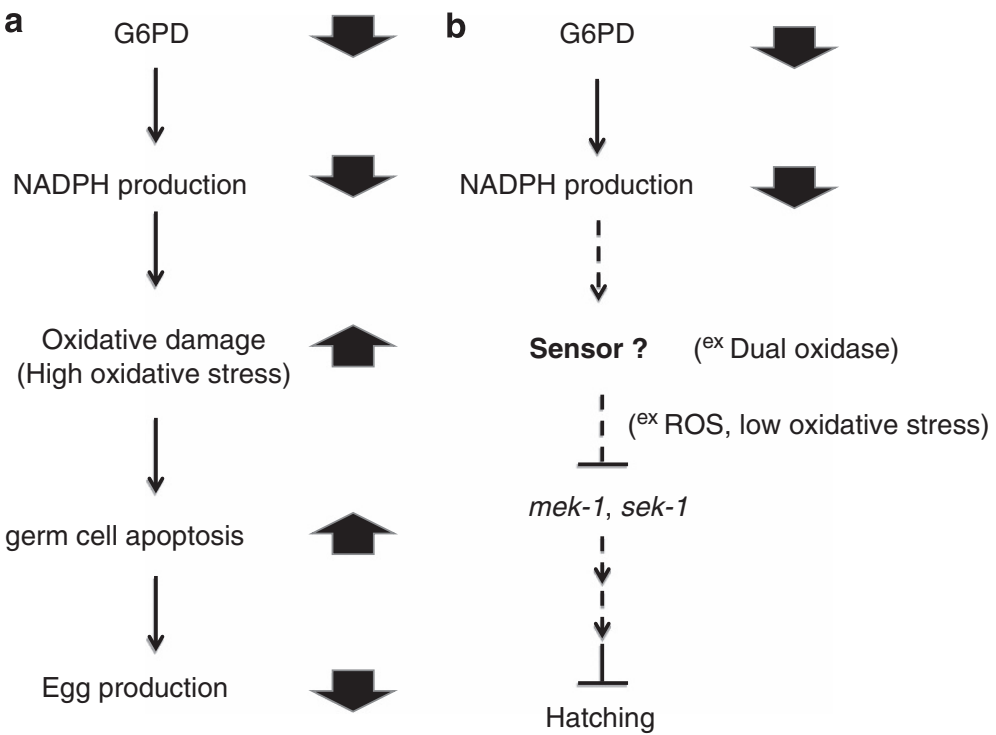

Figure 8 Proposed mechanism of defective oogenesis and embryogenesis induced by G6PD knockdown in C. elegans. G6PD deficiency reduces NADPH level, which may modulate signaling pathways of egg production and hatching. (a) The mechanism of G6PD knockdown-induced defective egg production is proposed. NADPH depletion impairs redox homeostasis as indicated by increased oxidative stress and DNA oxidative damage. As a result, the accumulated oxidative insult enhances germ cell death and leads to decreased egg production. (b) The mechanism of G6PD knockdown-induced defective hatching is proposed. Upon G6PD knockdown, the diminished NADPH reduces the activity of a yet to be identified sensor, for example dual oxidase. The decreased production of sensor-derived ROS, which serves as signaling molecules, activates mek-1 or sek-1 through negative regulation. In turn, activation of mek-1 or sek-1 impairs normal hatching possibly through multiple signaling pathways. Hence, the loss of function of mek-1 or sek-1 negates the deleterious effects on hatching due to G6PD deficiency in C. elegans 
G6PD-deficient $C$. elegans cannot be excluded. In the current study, short-term $\mathrm{H}_{2} \mathrm{O}_{2}$ enhances germ cell apoptosis in mock C. elegans in a dose-dependent manner (Figure 5a). However, the fact that $\mathrm{H}_{2} \mathrm{O}_{2}$ cannot further enhance germ cell apoptosis in G6PD-deficient $C$. elegans suggests that it may be due to the buildup of endogenous oxidative stress in the oocytes that enhances germ cell apoptosis. Consequently, the enhanced germ cell death may lead to reduced egg production in G6PDknockdown $C$. elegans as possible mechanism illustrated in Figure 8a. Nevertheless, the fact that vitamin E feeding fails to rescue the defective egg production and hatching in G6PDknockdown $C$. elegans under our experimental condition (data not shown), suggesting the modulation of the redox homeostasis is a very complicated matter and these findings are consistent with previous report that antioxidant supplementation often displays mixed or negative outcomes in clinical trials. ${ }^{34}$ Hence, the effect of increased oxidative stress or oxidative damage may be limited in playing a role in enhanced germ cell apoptosis caused by G6PD deficiency.

As p53-dependent DNA damage pathway ${ }^{35}$ and G6PD knockdown-induced alteration in MAPK activity are associated with cell demise, ${ }^{13}$ loss-of-function mutants of C. elegans p53 (cep-1) and MAPK pathways (pmk-1, sek-1 and mek-1) are scored for their egg production (Figure 6) and hatching (Figure 7) upon G6PD knockdown. The interpretation of the genetic analysis suggests that cep-1 is not required for the maintenance of normal egg production (Figure 6a). On the other hand, the p38 MAPK pathway, including pmk-1 and sek-1, is required for the maintenance of normal egg production (Figures $6 \mathrm{~b}$ and $\mathrm{c}$ ). As G6PD knockdown cannot further decrease egg production in pmk-1 mutant, this indicates that pmk-1 may act downstream of $g 6 p d$ in the same pathway for maintaining normal egg production (Figure 6b). While mek-1 is not involved in the maintenance of normal egg production (Figure $6 \mathrm{~d}$ ), the additive suppression of egg production in sek-1/g6pd(RNAi) double mutant suggests that sek-1 may function in parallel to g6pd rather than in the same pathway (Figure 6c). In general, p38 MAPK pathway is associated with diverse cellular functions, including immunity, apoptosis, stress response, and cell fate determination. The $C$. elegans pmk-1, a human p38 MAPK homologue, is activated by the mammalian MKK3/6 homologue sek-1, a member of MAPKK, which is downstream of nsy-1. The nsy-1-sek-1-pmk-1 cascade of p38 MAPK signaling is essential in the environmental response in C. elegans. ${ }^{36}$ In addition, the $C$. elegans mek-1, a member of MAPK kinase (MAPKK) and activator of c-Jun N-terminal kinase (JNK), is also involved in stress response. ${ }^{37}$ Hence, our results indicate that MAPK pathway is not directly associated with G6PD knockdown-induced defective egg production in C. elegans.

Despite MAPK pathway being not directly associated with egg production upon G6PD knockdown (Figures 6b-d), loss of function of sek-1 or mek-1 exhibits a substantial increase of hatching in G6PD-knockdown $C$. elegans embryos (8.3-fold and 9.6-fold, respectively) (Figure 7). Since G6PD is a major NADPH producing enzyme in cells, we hypothesized that there is a yet identified molecular sensor that respond to NADPH status in $C$. elegans. Upon G6PD knockdown, such NADPH sensor modulates the downstream signaling required for normal hatching. Such notion is not unprecedented. The translocation of the transcription factor, Nrf2 (Nuclear factor erythroid 2p45-related transcription factor), is modulated by a NADPH-requiring enzyme, NADPH oxidase (NOX). ${ }^{38}$ This exemplifies a positive regulation of signal transduction affected by NADPH. On the other hand, a recently identified NADPH sensor, HSCARG (NmrA (34-36)-like family domain containing protein 1 ), is shown to negatively regulate NF- $\kappa$ B function. ${ }^{39,40}$ Furthermore, the dual oxidase-derived oxidative burst is essential for extracellular matrix modification of sea urchin eggs during fertilization. ${ }^{41-43}$ Still more, it has been reported that ROS can negatively regulate Ras/MAPK pathway. ${ }^{44}$ In addition, p38 and ERK/MAPK have been shown to block bovine preimplantation embryogenesis. ${ }^{45}$ In order to clarify the role of MAPK in G6PD knockdown-induced defective hatching, we proposed a mechanism (Figure $8 b$ ) in which the depletion of G6PD-derived NADPH reduces the activity of the unknown NADPH sensor (for example, dual oxidase ${ }^{46}$ ) in $C$. elegans. The decreased ROS signaling (represents as low oxidative stress, in contrast to high oxidative stress that causes defective egg production in G6PD deficiency) activates MAPK activity through negative regulation. In turn, the activated MAPK impairs the hatching possibly through multiple signal transduction pathways. Hence, the inactivation of mek-1 or sek-1 negates the deleterious effects on hatching caused by G6PD knockdown in $C$. elegans. Indeed, the role of MAPK signaling in antagonizing essential gene for embryogenesis has been documented. The loss-of-function of MAPK pathways, including lin-45 (RAF), mek-2 (MEK), and mpk-1 (ERK), differentially rescue embryonic lethality of par-1 (partitioning defective) mutant embryos. ${ }^{47}$ However, how does the inactivation of sek1 or mek-1 actually suppress the defective hatching induced by G6PD knockdown remains to be elucidated.

All in all, we have reported a reproducible method to generate G6PD-deficient $C$. elegans by RNAi technique. This G6PD-knockdown animal model allows us to delineate the chronic effects of G6PD-deficiency at the multicellular organism level. The parental G6PD-knockdown C. elegans is viable and shows no major growth defect. However, G6PD-knockdown $C$. elegans displays enhanced germ cell apoptosis and reduced egg production as well as a severe defect in hatching. Mechanistic studies suggest that decreased egg production in G6PD-knockdown $C$. elegans could be attributed in part to increased oxidative stress and oxidative damage. In contrast to its toxic effect in egg production, ROS may play an important role as signal molecules to mediate MAPK pathway that in turn can affect hatching in $C$. elegans.

\section{Materials and Methods}

C. elegans strains. N2 (wild type), pmk-1(km25), sek-1(km4), mek-1(ks54),

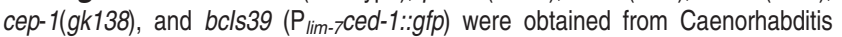
Genetics Center, University of Minnesota. All C. elegans strains were maintained on NGM agar plate seeded with bacterial lawn at $20^{\circ} \mathrm{C}$ according to standard protocols.

Multiple sequence alignment and phylogenetic analysis. The amino-acid sequence alignment and the phylogram of G6PD homologues were generated by online software Clustal W2 provided by EMBL-EBI (www.ebi.ac.uk). The abbreviation and accession number of each G6PD homologues are as followed: Hs, human (AAA92653); Mm, mouse (NP_032088); Dr, zebrafish (XP_699168); Dm, fruit fly (AAA99107); Ce, nematode (CAA97412); Sc, yeast (CAA93357); Ec, bacteria (AP_002472). 
Construction of G6PD-RNAi vector: L4440-G6PD. RNA extraction, competent cell preparation, plasmid DNA isolation, ligation, and transformation in this study were performed according to standard molecular cloning protocol. ${ }^{48}$ In brief, the total RNA of wild type C. elegans was isolated using Trizol (Invitrogen Carlsbad, CA, USA) and reverse transcribed to cDNA using reverse transcriptase-Superscript III (Invitrogen). The full length $C$. elegans G6PD (B0035.5) CDNA was amplified by PCR with primer pairs (forward primer: $5^{\prime}$ ATGGCATGCAAACGTCATTC-3'; reverse primer: $5^{\prime}$-CCCAACGAGGTTTCGATATT-3'). The PCR product of full length $C$. elegans G6PD was purified and ligated to $p C R$ 2.1-TOPO (Invitrogen). The construct was validated by restriction enzyme digestion and sequencing. The full length $C$. elegans G6PD fragment was ligated to $L 4440$ (L4440-G6PD), and later transformed into E. coli HT115 (DE3).

RNAi knockdown. The procedure of RNAi knockdown by dsRNA feeding was performed based on standard protocol. ${ }^{24} \mathrm{~N} 2$ hermaphrodites were cultured at $20^{\circ} \mathrm{C}$ on NGM plate seeded with E. coli OP50. The gravid adults were harvested and bleached $(0.5 \mathrm{M} \mathrm{NaOH}$ and $1 \% \mathrm{NaOCl})$ to obtain eggs. The bleached eggs were synchronized to $\mathrm{L} 1$ in $\mathrm{M} 9$ buffer at $20^{\circ} \mathrm{C}$ for $16 \mathrm{~h}$ and transferred to IPTG (1 mM) containing NGM plate seeded with E. coli HT115 (DE3)/ L4440 and HT115 (DE3) / L4440-G6PD at $20^{\circ} \mathrm{C}$ for 3 days to obtain staged adults of mock and G6PD-knockdown C. elegans, respectively.

G6PD activity assay. The G6PD activity of adult $C$. elegans was assayed spectrophotometrically at $340 \mathrm{~nm}$ by the reduction of $\mathrm{NADP}^{+}$in the presence of glucose 6-phosphate as previously described with modification. ${ }^{11}$ In brief, staged first-day adults were harvested from RNAi NGM plate with washing buffer (1X PBS supplemented with $0.1 \%$ Tween 20 ) followed by washing and pelleting twice to remove bacteria. The worms were resuspended in extraction buffer $(20 \mathrm{mM}$ Tris$\mathrm{HCl}, \mathrm{pH} 8.0,3 \mathrm{mM}$ magnesium chloride, $1 \mathrm{mM}$ EDTA, $0.02 \% \beta$-mercaptoethanol, $1 \mathrm{mM}$ e-aminocaproic acid and $0.1 \%$ Triton X-100). The worm suspension was chilled immediately on ice and disrupted by sonication (Amplitude: 10\%, pulse: $2 \mathrm{~s}$ with 5-s intervals for 20 cycles) (VCX400, Sonics and Materials, Danbury, CT, USA). The crude lysates were centrifuged at 12000 r.p.m. for $15 \mathrm{~min}$ at $4{ }^{\circ} \mathrm{C}$ (Centrifuge 5417R, Eppendorf, Hamburg, Germany) and the supernatants (protein-containing lysate) were collected. Protein concentration of the lysate was determined by Bradford method (Bio-Rad, Hercules, CA, USA). A typical assay mixture consisted of $100 \mu \mathrm{g}$ of protein lysate in $1 \mathrm{ml}$ of assay buffer $(50 \mathrm{mM}$ Tris- $\mathrm{HCl} \mathrm{pH} \mathrm{8,50} \mathrm{mM} \mathrm{MgCl} 2,4 \mathrm{mM} \mathrm{NADP}{ }^{+}, 4 \mathrm{mM}$ glucose 6-phosphate). The change of absorbance at $340 \mathrm{~nm}$ in each sample was measured spectrophotometrically for $15 \mathrm{~min}$ at $37^{\circ} \mathrm{C}$.

Quantitative real-time PCR. Quantitative real-time PCR was performed by using iQ5 real-time thermal cycler (Bio-Rad) and SYBR PCR Premix reagent (Yeastern Biotechnology, Taipei, Taiwan). Primers were designed using Beacon designer software (Bio-Rad) or Primer $3{ }^{49}$ In brief, reaction mixtures contained $1 \mu \mathrm{g}$ of cDNA prepared from total mRNA extract, diluted primers, and SYBR PCR Premix in PCR microcentrifuge tube. The thermal cycle procedure was as followed: $95^{\circ} \mathrm{C}$ for $10 \mathrm{~min}, 40$ cycles of $95^{\circ} \mathrm{C}$ for $15 \mathrm{~s}$ and $60^{\circ} \mathrm{C}$ for $1 \mathrm{~min}$. Relative gene expression ( $\mathrm{g} 6 \mathrm{pd}$ : forward primer, $5^{\prime}$-atgctcttgctgttgttcacatc- $3^{\prime}$; reverse primer, $5^{\prime}$-cgctttaattcaccagacggatag- $3^{\prime}$ ) was normalized against threshold cycle (Ct) values of the housekeeping gene (ef-1 $\alpha$ : forward primer, $5^{\prime}$-acattgtcgtcatcggacatgtcgactc- $3^{\prime}$; reverse primer, $5^{\prime}$-cgagaacccaggcgtacttgaaggatc- $\left.3^{\prime}\right)$. The relative index $\left(2^{-\Delta \Delta C t}\right)$ was calculated by comparing the average expression levels for control samples with the index defined as 1.00 .

Western blot. The C. elegans protein lysate extracted from staged adults were resolved by SDS-PAGE and immunoblotting against a rabbit antiserum to human G6PD, C. elegans CEP-1 (Santa Cruz Biotechnology, Dallas, TX, USA), human actin (Santa Cruz Biotechnology), or C. elegans tubulin (Santa Cruz Biotechnology) according to the instructions provided by manufacturers.

DNA oxidative damage analysis. The $8-\mathrm{OHdG}$ was measured in staged adults $C$. elegans based on a published protocol. ${ }^{11}$ In brief, staged first-day adults were harvested, washed, and resuspended in TE buffer followed by sonication and centrifugation at 12000 r.p.m. for $15 \mathrm{~min}$ at $4{ }^{\circ} \mathrm{C}$. The supernatant was incubated with $0.7 \mathrm{mg} / \mathrm{ml}$ RNase $A, 0.46 \%$ SDS, and $0.1 \mathrm{mM}$ deferoxamine mesylate at $37^{\circ} \mathrm{C}$ for $1 \mathrm{~h}$. It was followed by the addition of $0.36 \mathrm{mg} / \mathrm{ml}$ of proteinase $\mathrm{K}$ for $16-18 \mathrm{~h}$ in dark at room temperature on a rotating roller drum. The DNA was extracted by phenol/ chloroform/isoamylalcohol $(25: 24: 1)$ and precipitated with $3 \mathrm{M}$ sodium acetate ( $\mathrm{pH}$ 5.2). The DNA pellet was sequentially washed by 99.5 and $70 \%$ ethanol. The washed DNA was resuspended in $20 \mathrm{mM}$ sodium acetate (pH 5.2) and digested to nucleotide level for $2 \mathrm{~h}$ at $37^{\circ} \mathrm{C}$ with 20 units of nuclease $\mathrm{P1}$. Subsequently, 6 units of alkaline phosphatase in $1 \mathrm{M}$ Tris buffer ( $\mathrm{pH} 8.5$ ) were added for $1.5 \mathrm{~h}$ at $37^{\circ} \mathrm{C}$. Prior to HPLC analysis, hydrolysate was subjected to filtration with Microcon YM-10 (EMD Millipore, Billerica, MA, USA) to remove proteins and and other macromolecules. The filtrate containing nucleosides was separated by a reverse-phase HPLC system (ESA, Inc., Chelmsford, MA, USA) using a C8 column ( $3 \mu \mathrm{m}, 4.6 \times 150 \mathrm{~mm}$; YMC-BD) and was eluted at a flow rate of $1.0 \mathrm{ml} / \mathrm{min}$ with $10 \%$ methanol in $20 \mathrm{mM}$ sodium acetate buffer (pH 5.2) as mobile phase. The amount of $8-\mathrm{OHdG}$ and $\mathrm{dG}$ were detected with an ESA Coulochem II electrochemical detector (ESA, Inc., USA). The standards 8-OHdG and $d G$ were used in this assay. The $8-O H d G$ level was represented as the number of $8-\mathrm{OHdG}$ molecules per $10^{6} \mathrm{dG}$.

Determination of egg production and hatching. Staged L4 hermaphrodites of mock and G6PD-knockdown $C$. elegans were transferred to new RNAi plate in triplicate. Subsequently, these hermaphrodites were transferred to fresh RNAi NGM plates every $24 \mathrm{~h}$ during egg laying period. Immediately after transfer, the eggs laid on plate were scored manually under dissecting microscope. To determine hatching, live progeny was counted 3 days after the parents were removed. The hatching percentage is calculated as the number of hatched progeny divided by the total egg production.

Short-term hydrogen peroxide treatment. Staged young adults of mock and G6PD-knockdown $C$. elegans were harvested and treated with various concentrations of $\mathrm{H}_{2} \mathrm{O}_{2}$ prepared in PBS for $30 \mathrm{~min}$ at room temperature on a test tube rotator (Snijders, Tilburg, Netherlands). Immediately after the treatment, the worms were pelleted and rinsed with PBS to remove the residual $\mathrm{H} 2 \mathrm{O} 2$. The treated C. elegans was transferred to fresh RNAi NGM plate for recovery for $2 \mathrm{~h}$ followed by picking hermaphrodites for scoring apoptotic germ cells and egg production.

Quantification of germ cell apoptosis. Germ cell apoptosis was visualized based on CED-1::GFP, a specific reporter, which highlights the somatic sheath cell surrounded apoptotic germ cells upon engulfment by using bcls39 strain $\left(\mathrm{P}_{\text {lim- }}\right.$ ced-1::gfp) ${ }^{25}$ Staged young adult hermaphrodites of mock and G6PDknockdown $C$. elegans grown at $20^{\circ} \mathrm{C}$ were harvested from RNAi NGM plate. These worms were washed with PBS and anesthetized with $2 \%$ levamisole followed by mounting on $2 \%$ agarose pad on glass slides. Fluorescent images were taken by using epifluorescence microscope (Leica DM 2500; Leica, Wetzlar, Germany) coupled with CCD camera (Photometrics, Coolsnap K4, Tucson, AZ, USA) and analyzed by imaging software (Metamorph 6.1r0; Molecular Devices, Sunnyvale, CA, USA). The number of apoptotic germ cells was determined by counting green fluorescent germ cells in each gonad. For short-term oxidant treatment, $b c / s 39$ strain was pretreated with $\mathrm{H}_{2} \mathrm{O}_{2}$ at young adult stage as previously described.

Oxidative stress measurement. The oxidative stress measurement in C. elegans was performed according to a published protocol. ${ }^{50}$ Briefly, the ROS was detected in vivo in staged first-day adults $C$. elegans by staining with 2', 7'-dichlorodihydrofluoroscein diacetate (Molecular Probes, Eugene, OR, USA). Nonfluorescent DCFDA is a freely cell permeable dye, which can be readily converted to fluorescent $2^{\prime}, 7^{\prime}$-dichlorofluorescein owing to the interaction with intracellular $\mathrm{H}_{2} \mathrm{O}_{2}$. C. elegans samples in triplicate were incubated in 96 well plate containing $50 \mu \mathrm{M}$ DCFDA in $\mathrm{M} 9$ buffer at room temperature $\left(25^{\circ} \mathrm{C}\right)$ in a fluorescent microplate reader (Spectra MAX Gemini, Molecular Devices). C. elegans samples were read every $2 \mathrm{~min}$ for $5 \mathrm{~h}$ for quantification of fluorescence at $485 \mathrm{~nm}$ (excitation) and $530 \mathrm{~nm}$ (emission). After the assay, C. elegans samples were harvested to determine protein concentration for normalization.

Statistical analysis. Where applicable, data were presented as means \pm S.D. Statistical difference between mock and G6PD-knockdown C. elegans was analyzed by Student's $t$-test. Comparisons between different concentrations of oxidant treatment were evaluated by one-way analysis of variance followed by Tukey's multiple comparison test. Values of $P<0.05$ were considered statistically significant. 


\section{Conflict of Interest}

The authors declare no conflict of interest.

Acknowledgements. This study was carried out with financial supports from the National Science Council of Taiwan (NSC100-2320-B-182-010-MY3) to DTYC and (NSC100-2511-S-182-001) to SJL; Ministry of Education of Taiwan (EMRPD1B0321, EMRPD1B0461) to DTYC and (EMRPD1B0081) to SJL; and Chang Gung University (CMRPD190422, CMRPD190423) to DTYC. We thank Caenorhabditis Genetics Center (CGC) for providing strains of worms.

1. Salati LM, Amir-Ahmady B. Dietary regulation of expression of glucose-6-phosphate dehydrogenase. Annu Rev Nutr 2001; 21: 121-140.

2. Ho HY, Cheng ML, Chiu DT. Glucose-6-phosphate dehydrogenase-from oxidative stress to cellular functions and degenerative diseases. Redox Rep 2007; 12: 109-118.

3. Ho HY, Cheng ML, Chiu DT. G6PD—an old bottle with new wine. Chang Gung Med J 2005; 28: 606-612

4. Beutler E. G6PD deficiency. Blood 1994; 84: 3613-3636.

5. Pantaleo A, Ferru E, Carta F, Mannu F, Simula LF, Khadjavi A et al. Irreversible AE1 tyrosine phosphorylation leads to membrane vesiculation in G6PD deficient red cells. PLoS One 2011; 6: e15847.

6. Shimo H, Nishino T, Tomita M. Predicting the kinetic properties associated with redox imbalance after oxidative crisis in G6PD-deficient erythrocytes: a simulation study. Adv Hematol 2011; 2011: 398945.

7. Arese P, De Flora A. Pathophysiology of hemolysis in glucose-6-phosphate dehydrogenase deficiency. Semin Hematol 1990; 27: 1-40.

8. Sirdah M, Reading NS, Perkins SL, Shubair M, Aboud L, Prchal JT. Hemolysis and Mediterranean G6PD mutation (c.563 C > T) and c.1311 C > T polymorphism among Palestinians at Gaza Strip. Blood Cells Mol Dis 2012; 48: 203-208.

9. Tanphaichitr VS, Hirono A, Pung-amritt P, Treesucon A, Wanachiwanawin W. Chronic nonspherocytic hemolytic anemia due to glucose-6-phosphate dehydrogenase deficiency: report of two families with novel mutations causing G6PD Bangkok and G6PD Bangkok Noi. Ann Hematol 2011; 90: 769-775.

10. Ho HY, Cheng ML, Lu FJ, Chou YH, Stern A, Liang CM et al. Enhanced oxidative stress and accelerated cellular senescence in glucose-6-phosphate dehydrogenase (G6PD)-deficient human fibroblasts. Free Radic Biol Med 2000; 29: 156-169.

11. Cheng ML, Ho HY, Wu YH, Chiu DT. Glucose-6-phosphate dehydrogenase-deficient cells show an increased propensity for oxidant-induced senescence. Free Radic Biol Med 2004; 36: 580-591.

12. Gao LP, Cheng ML, Chou HJ, Yang YH, Ho HY, Chiu DT. Ineffective GSH regeneration enhances G6PD-knockdown Hep G2 cell sensitivity to diamide-induced oxidative damage. Free Radic Biol Med 2009; 47: 529-535.

13. Lin CJ, Ho HY, Cheng ML, You TH, Yu JS, Chiu DT. Impaired dephosphorylation renders G6PD-knockdown HepG2 cells more susceptible to $\mathrm{H}(2) \mathrm{O}(2)$-induced apoptosis. Free Radic Biol Med 2010; 49: 361-373.

14. Tsai KJ, Hung IJ, Chow CK, Stern A, Chao SS, Chiu DT. Impaired production of nitric oxide, superoxide, and hydrogen peroxide in glucose 6-phosphate-dehydrogenasedeficient granulocytes. FEBS Lett 1998; 436: 411-414.

15. Ho HY, Cheng ML, Weng SF, Chang L, Yeh TT, Shih SR et al. Glucose-6-phosphate dehydrogenase deficiency enhances enterovirus 71 infection. J Gen Virol 2008; 89(Pt 9): 2080-2089.

16. Wu YH, Tseng CP, Cheng ML, Ho HY, Shih SR, Chiu DT. Glucose-6-phosphate dehydrogenase deficiency enhances human coronavirus 229E infection. J Infect Dis 2008; 197: 812-816.

17. Johnson FB, Sinclair DA, Guarente L. Molecular biology of aging. Cell 1999; 96: 291-302.

18. Yamada T, Egashira N, Bando A, Nishime Y, Tonogai Y, Imuta M et al. Activation of p38 MAPK by oxidative stress underlying epirubicin-induced vascular endothelial cell injury. Free Radic Biol Med 2012; 52: 1285-1293.

19. C. elegans Sequencing Consortium. Genome sequence of the nematode C. elegans: a platform for investigating biology. Science 1998; 282: 2012-2018.

20. Jorgensen EM, Mango SE. The art and design of genetic screens: caenorhabditis elegans. Nat Rev Genet 2002; 3: 356-369.

21. Antoshechkin I, Sternberg PW. The versatile worm: genetic and genomic resources for Caenorhabditis elegans research. Nat Rev Genet 2007; 8: 518-532.

22. Ankeny RA. The natural history of Caenorhabditis elegans research. Nat Rev Genet 2001; 2: $474-479$.

23. Filosa S, Fico A, Paglialunga F, Balestrieri M, Crooke A, Verde P et al. Failure to increase glucose consumption through the pentose-phosphate pathway results in the death of glucose-6-phosphate dehydrogenase gene-deleted mouse embryonic stem cells subjected to oxidative stress. Biochem J 2003; 370(Pt 3): 935-943.

24. Kamath RS, Fraser AG, Dong Y, Poulin G, Durbin R, Gotta M et al. Systematic functional analysis of the Caenorhabditis elegans genome using RNAi. Nature 2003; 421: 231-237.
25. Zhou Z, Hartwieg E, Horvitz HR. CED-1 is a transmembrane receptor that mediates cell corpse engulfment in C. elegans. Cell 2001; 104: 43-56.

26. Calafato S, Swain S, Hughes S, Kille P, Sturzenbaum SR. Knock down of Caenorhabditis elegans cutc-1 exacerbates the sensitivity toward high levels of copper. Toxicol Sci 2008; 106: 384-391.

27. Wu Q, He K, Liu P, Li Y, Wang D. Association of oxidative stress with the formation of reproductive toxicity from mercury exposure on hermaphrodite nematode Caenorhabditis elegans. Environ Toxicol Pharmacol 2011; 32: 175-184.

28. Kumsta C, Thamsen M, Jakob U. Effects of oxidative stress on behavior, physiology, and the redox thiol proteome of Caenorhabditis elegans. Antioxid Redox Signal 2011; 14: 1023-1037.

29. Fraenkel DG, Vinopal RT. Carbohydrate metabolism in bacteria. Annu Rev Microbiol 1973; 27: $69-100$.

30. Thomas D, Cherest H, Surdin-Kerjan Y. Identification of the structural gene for glucose6-phosphate dehydrogenase in yeast. Inactivation leads to a nutritional requirement for organic sulfur. EMBO J 1991; 10: 547-553.

31. Hecker PA, Lionetti V, Ribeiro RF Jr., Rastogi S, Brown BH, O'Connell KA et al. Glucose 6-phosphate dehydrogenase deficiency increases redox stress and moderately accelerates the development of heart failure. Circ Heart Fail 2013; 6: 118-126.

32. Longo L, Vanegas OC, Patel M, Rosti V, Li H, Waka J et al. Maternally transmitted severe glucose 6-phosphate dehydrogenase deficiency is an embryonic lethal. EMBO J 2002; 21: 4229-4239.

33. Salinas LS, Maldonado E, Navarro RE. Stress-induced germ cell apoptosis by a p53 independent pathway in Caenorhabditis elegans. Cell Death Differ 2006; 13: 2129-2139.

34. Berger RG, Lunkenbein S, Strohle A, Hahn A. Antioxidants in food: mere myth or magic medicine? Crit Rev Food Sci Nutr 2012; 52: 162-171.

35. Gartner A, Boag PR, Blackwell TK. Germline survival and apoptosis. WormBook $20081-20$.

36. Wang S, Wu L, Wang Y, Luo X, Lu Y. Copper-induced germline apoptosis in Caenorhabditis elegans: the independent roles of DNA damage response signaling and the dependent roles of MAPK cascades. Chem Biol Interact 2009; 180: 151-157.

37. Koga M, Zwaal R, Guan KL, Avery L, Ohshima Y. A Caenorhabditis elegans MAP kinase kinase, MEK-1, is involved in stress responses. EMBO J 2000; 19: 5148-5156.

38. Sekhar KR, Crooks PA, Sonar VN, Friedman DB, Chan JY, Meredith MJ et al. NADPH oxidase activity is essential for Keap1/Nrf2-mediated induction of GCLC in response to 2-indol-3-yl-methylenequinuclidin-3-ols. Cancer Res 2003; 63: 5636-5645.

39. Gan Q, Li T, Hu B, Lian M, Zheng X. HSCARG inhibits activation of NF-kappaB by interacting with IkappaB kinase-beta. J Cell Sci 2009; 122(Pt 22): 4081-4088.

40. Zhang M, Hu B, Li T, Peng Y, Guan J, Lai S et al. A CRM1-dependent nuclear export signal controls nucleocytoplasmic translocation of HSCARG, which regulates NF-kappaB activity. Traffic 2012; 13: 790-799.

41. Wong JL, Creton R, Wessel GM. The oxidative burst at fertilization is dependent upon activation of the dual oxidase Udx1. Dev Cell 2004; 7: 801-814.

42. Wong JL, Wessel GM. Reactive oxygen species and Udx1 during early sea urchin development. Dev Biol 2005; 288: 317-333.

43. Wong JL, Wessel GM. Free-radical crosslinking of specific proteins alters the function of the egg extracellular matrix at fertilization. Development 2008; 135: 431-440.

44. Morey M, Serras F, Baguna J, Hafen E, Corominas M. Modulation of the Ras/MAPK signalling pathway by the redox function of selenoproteins in Drosophila melanogaster. Dev Biol 2001; 238: 145-156.

45. Madan P, Calder MD, Watson AJ. Mitogen-activated protein kinase (MAPK) blockade of bovine preimplantation embryogenesis requires inhibition of both $\mathrm{p38}$ and extracellular signal-regulated kinase (ERK) pathways. Reproduction 2005; 130: 41-51.

46. Yang HC, Cheng ML, Ho HY, Chiu DT. The microbicidal and cytoregulatory roles of NADPH oxidases. Microbes Infect 2011; 13: 109-120.

47. Spilker AC, Rabilotta A, Zbinden C, Labbe JC, Gotta M. MAP kinase signaling antagonizes PAR-1 function during polarization of the early Caenorhabditis elegans embryo. Genetics 2009; 183: 965-977.

48. Sambrook J, Russell DW. Molecular Cloning, A Laboratory Manual. 3rd edn, Cold Spring Harbor Laboratory: New York, 2001.

49. Skaletsky SRaHJ. Primer3 on the WWW for general users and for biologist programmers. In: Krawetz S, Misener S (eds) Bioinformatics Methods and Protocols: Methods in Molecular Biology. Humana Press: Totowa, NJ, 2000. pp 365-386.

50. Liao VH, Yu CW, Chu YJ, Li WH, Hsieh YC, Wang TT. Curcumin-mediated lifespan extension in Caenorhabditis elegans. Mech Ageing Dev 2011; 132: 480-487.

(c) (i) $\Theta$ Cell Death and Disease is an open-access journal published by Nature Publishing Group. This work is licensed under a Creative Commons Attribution-NonCommercialNoDerivs 3.0 Unported License. To view a copy of this license, visit http://creativecommons.org/licenses/by-nc-nd/3.0/ 